\title{
Modulating the Frontier Orbitals of an Aluminylene for Facile Dearomatization of Inert Arenes
}

\author{
Xin Zhang, Liu Leo Liu* \\ Dedicated to Professor Douglas W. Stephan \\ [*] Dr. X. Zhang; Prof. Dr. L. L. Liu \\ Department of Chemistry and Shenzhen Grubbs Institute, Southern University of Science and Technology, Shenzhen 518055, China \\ E-mail: liuleoliu@sustech.edu.cn
}

\begin{abstract}
Lewis bases are well known to stabilize electron-deficient species. We demonstrate herein that the redox property of a monocoordinated aluminylene $\mathbf{1}$ featuring only four valence electrons for the shell of Al can be boosted by a Lewis base. The coordination of 1 with an $\mathrm{N}$-heterocyclic carbene (NHC) effectively shrinks the HOMO-LUMO gap, thereby enhancing the reactivity of the ensuing acyclic mono-NHC-stabilized aluminylene $\mathbf{2}$, which is isoelectronic with singlet carbenes. Moreover, such base coordination completely reverses the predominant chemical reactivity (i.e. electrophilicity/nucleophilicity) of aluminylenes. In marked contrast to 1,2 readily undergoes a $[4+1]$ cycloaddition reaction with naphthalene and biphenylene at room temperature. Strikingly, the enhanced ambiphilic nature of $\mathrm{Al}$ in $\mathbf{2}$ also enables facile cleavage of aromatic $\mathrm{C}-\mathrm{C}$ bonds of inert arenes in both intra- and intermolecular fashion affording $\mathbf{3}$ and $\mathbf{5}$. The formation of $\mathbf{5}$ represents the first example of the cleavage of aromatic $\mathrm{C}(3)-\mathrm{C}(4)$ bond in biphenylene by a single atom center.
\end{abstract}

\section{Introduction}

The last two decades have witnessed a significant development in transition-metal-free small molecule activation. ${ }^{[1]}$ Representative examples involve heavier group 14 dimetallynes and dimetallenes, ${ }^{[2]}$ stable singlet carbenes and their analogs, ${ }^{[3]}$ as well as frustrated Lewis pairs (FLPs). ${ }^{[4]}$ Such main group species feature a lone pair of electrons and a vacant orbital, a combination that exhibits ambiphilic reactivity and transitionmetal-like behaviors, ${ }^{[1 a]}$ thus enabling the activation of a wide range of small molecules with enthalpically strong bonds (e.g. $\mathrm{H}_{2}$, $\mathrm{NH}_{3}$, arenes and even $\left.\mathrm{N}_{2}\right) \cdot{ }^{[2-5]}$

Despite the high reactivity of singlet carbenes (I) (Figure 1a), with right substituents, many types of carbenes are bottle-able at ambient temperature. ${ }^{[3 \mathrm{~d}, 3 \mathrm{f}, 3 \mathrm{~h}, 3 \mathrm{k}]}$ In contrast, the chemistry of stable neutral aluminium analogs of carbenes (II and III) is in its infancy. ${ }^{[3 \mathrm{c}, 3 \mathrm{~g}, 3 \mathrm{j}, 3 \mathrm{~m}, 3 \mathrm{n}]}$ The first known $\mathrm{Al}(\mathrm{I})$ species, namely $\left(\mathrm{Cp}^{\star} \mathrm{Al}\right)_{4}$ was isolated by Schnöckel in 1991; it equilibrates with monomeric $\mathrm{Cp}^{*} \mathrm{Al}(\mathbf{A})$ in solutions (Figure $\left.1 \mathrm{~b}\right){ }^{[6]}$ With a bulkier $\mathrm{Cp}$ ligand (i.e. $\left.\left({ }^{\mathrm{B} u}\right)_{3} \mathrm{C}_{5} \mathrm{H}_{2}\right)$, Braunschweig described that the equilibrium exclusively shifts to the monomer $\left({ }^{t} \mathrm{Bu}\right)_{3} \mathrm{C}_{5} \mathrm{H}_{2} \mathrm{Al} \cdot{ }^{[7]}$ In 2000 , Roesky isolated a stable neutral $\mathrm{Al}(\mathrm{I})$ complex $\mathrm{HC}[(\mathrm{CMe})(\mathrm{NDipp})]_{2} \mathrm{Al}(\mathrm{B})$ (Dipp $=2,6$-diisopropylphenyl), ${ }^{[8]}$ while afterwards an analogous species $\mathrm{HC}\left[\left(\mathrm{C}^{t} \mathrm{Bu}\right)(\mathrm{NDipp})\right]_{2} \mathrm{Al}$ was reported by Cui. ${ }^{\left[{ }^{[]}\right.} \mathbf{B}$ exhibits aluminylene character and its reactivity towards a variety of small molecules has been extensively studied. $\left.{ }^{[1 \mathrm{~d},}, 1 \mathrm{~h}, 3 \mathrm{i}, 3 \mathrm{~m}, 10\right]$ Driess characterized an $\mathrm{Al}(\mathrm{I})$ bromide species in the coordination sphere of one $\mathrm{Fe}(\mathrm{CO})_{4}$ and two NHC ligands. ${ }^{[11]}$ In 2019, Braunschweig stabilized an $\mathrm{Al}(\mathrm{I})$ hydride $\mathbf{C}$ by ligation of two cyclic (alkyl)(amino)carbenes. ${ }^{[12]}$ More recently, by employing a sterically demanding terphenyl ligand a unique free aluminylene D was disclosed by Power and Tuononen. ${ }^{[13]}$ D reveals high reactivity for facile cleavage of hydrogen, ${ }^{[13]}$ while the reaction of D with $\mathrm{ArN}_{3}\left(\mathrm{Ar}=\mathrm{C}_{6} \mathrm{H}_{3}-2,6-\left(\mathrm{C}_{6} \mathrm{H}_{2}-2,4,6-\mathrm{Me}_{3}\right)_{2}\right)$ afforded the first stable iminoalane with an $\mathrm{Al} \equiv \mathrm{N}$ triple bond. ${ }^{\left[{ }^{[4]}\right.}$ Shortly thereafter, we $^{[15]}$ and Hinz ${ }^{[16]}$ independently reported an isolable $\mathrm{N}$ aluminylene $\mathbf{1}$. The coordination chemistry of $\mathbf{1}$ with transition

(a)

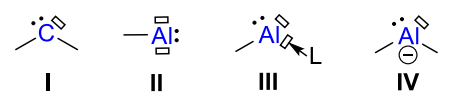

(b)

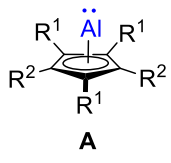

$\left(R^{1}=R^{2}=\right.$ Me; transient $)$ $\left(R^{1}={ }^{t} B u ; R^{2}=H\right.$; isolable $)$<smiles>CC1(C)CC(C)(C)N([Pb])C1=CC1N([PH2+])C(C)(C)CC1(C)C</smiles>

C
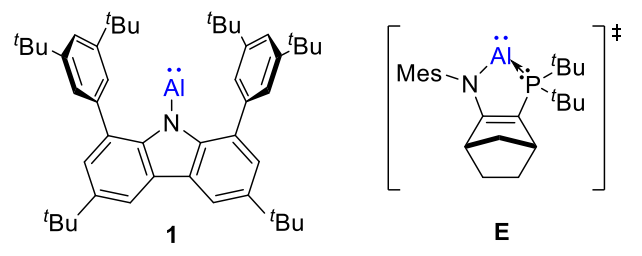

(c) Present work:

一鿖: $\stackrel{\mathrm{L}}{\longrightarrow} \quad \dot{A}_{\mathcal{R}_{\mathrm{L}}}$ stabilization or activation at Al?

- Crystalline acyclic mono-base-stabilized aluminylene - Small HOMO-LUMO gap

- [4+1] cycloaddtions with inert arenes

- Facile cleavage of aromatic C-C bonds

Figure 1. (a) Representations of singlet carbenes I, aluminylenes II, monobase-stabilized aluminylenes III, and aluminyl anions IV. (b) Examples of transition-metal-free monomeric Al(I) species A-E and 1. Dipp =2,6diisopropylphenyl. Mes = mesityl. (c) Present work.

metals has been documented. ${ }^{[15]}$ In addition, an intriguing family of nucleophilic anionic aluminyl compounds (IV) ${ }^{[3 n]}$ (Figure 1a) have been rapidly developed by the groups of Aldridge, ${ }^{[17]}$ Goicoechea, ${ }^{[17 a, 17 b]}$ Coles, ${ }^{[18]}$ Hill,,${ }^{[19]}$ McMullin, ${ }^{[18 b,}{ }^{19]}$ Kinjo, ${ }^{[20]}$ Yamashita, ${ }^{[21]}$ and Harder. ${ }^{[22]}$

While aluminylenes (II) are often viewed as the aluminium analogs of carbenes (Figure 1a), they are not isoelectronic with carbenes as there are two vacant orbitals at Al. To fulfil the isoelectronic criteria, one of these vacant orbitals should be filled by a neutral Lewis base, as illustrated by III. Although one of the extreme bonding situations of $\mathbf{B}$ can belong to type III, stable genuine mono-base-stabilized aluminylenes remain elusive. Unlike isolable borylenes, ${ }^{[23]}$ reduction of carbene-alane adducts (e.g. $\mathrm{Me}_{2} I \operatorname{PrAIRX}{ }_{2}, \mathrm{R}=$ silyl or aryl, $\mathrm{X}=\mathrm{Br}$ or $\mathrm{I}, \mathrm{Me}_{2} \mathrm{IPr}=1,3-$ diisopropyl-4,5-dimethyl-imidazolin-2-ylidene; CAACAICl ${ }_{3}, \mathrm{CAAC}$ $=\quad 1$-(2,6-diisopropylphenyl)-3,3,5,5-tetramethyl-pyrrolidin-2- 
ylidene) has been shown to produce either $\mathrm{Me}_{2} \mathrm{IPr}$-dialumene adducts by Inoue ${ }^{[24]}$ or a bis-CAAC-stabilized aluminium radical by Roesky, Frenking et al. ${ }^{[25]}$ Based on chemical trapping experiments, Cowley and Krämer indicated the transient existence of an amidophosphine-supported aluminylene $\mathbf{E}$ that is in equilibrium with its dimeric dialumene in solutions. ${ }^{[26]} \mathbf{E}$ has been described as a highly fleeting species, defying direct observation. ${ }^{[26-27]}$ In the present work, we propose a general concept for boosting the redox activity of aluminylenes by simple addition of a Lewis basic NHC, leading to an isolable acyclic NHCstabilized aluminylene 2 (Figure 2). Interestingly, the NHC coordination effectively shrinks the HOMO-LUMO gap of 2 and thus significantly enhances the ambiphilicity at Al. This results in unprecedented dearomatization of inert arenes by a single neutral Al center.

(a)

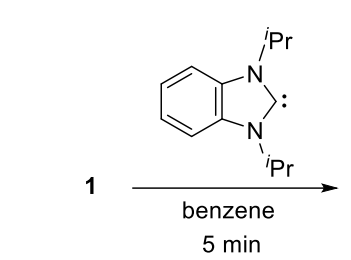

$\triangle \mathrm{E}_{\mathrm{H}-\mathrm{L}}: 5.97 \mathrm{eV}$ white solid

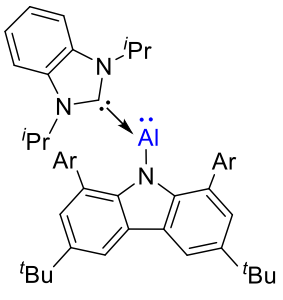

2 dark solid

(b)

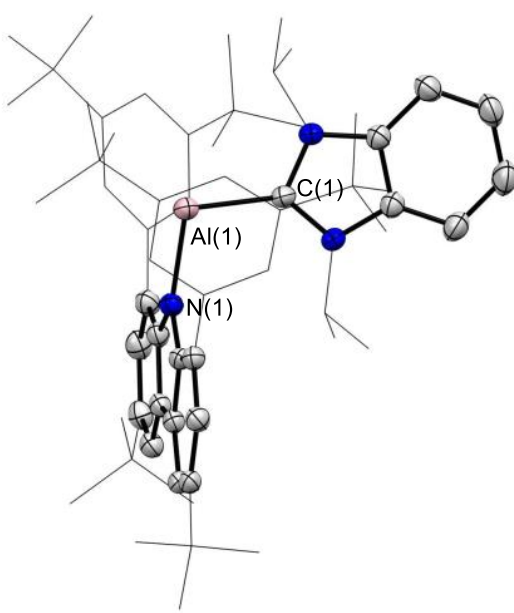

Figure 2. (a) Synthesis of 2. Ar= 3,5-di-tert-butylphenyl. (b) Solid-state structure of 2 . Hydrogen atoms are omitted for clarity. Thermal ellipsoids are set at the $40 \%$ probability level.

\section{Results and Discussion}

Although 1 has an electron-deficient aluminylene center, it was found completely inert towards weakly coordinating solvents (i.e., THF and $\mathrm{Et}_{2} \mathrm{O}$ ), as indicated by ${ }^{1} \mathrm{H}$ NMR spectroscopic analyses (Figure S14). Nonetheless, the combination of $\mathbf{1}$ with an equimolar amount of 1,3-di-isoproplylbenzimidazole-2-ylidene ( $\mathrm{Pr}_{2}$-bimy) in toluene immediately gave rise to a dark solution (initially colorless) (Figure 2a). After workup, species 2 was isolated as a dark turquoise/black crystalline solid in $59 \%$ yield. The structure of $\mathbf{2}$ as a ${ }^{i} \mathrm{Pr}_{2}$-bimy-stabilized aluminylene was elucidated by single crystal X-ray diffraction (Figure $2 b) .{ }^{[28]}$ In the solid state, the $\mathrm{N}(1)$ adapts in a planar geometry with the sum of angles of $359.7^{\circ}$. The bond lengths of $\mathrm{Al}(1)-\mathrm{C}(1)$ and $\mathrm{Al}(1)-\mathrm{N}(1)$ are $2.244(2)$ and $1.980(1) \AA$, respectively. The latter is slightly longer than those of $\mathbf{1}(1.913(9) \AA)^{[15]}$ and $\mathbf{B}(\mathrm{R}=\mathrm{Me})(1.958$ (2) $\AA)^{[8]}$ The bond angle of $\mathrm{C}(1)-\mathrm{Al}(1)-\mathrm{N}(1)$ is $97.66(6)^{\circ}$. 2 represents the first example of a genuine acyclic mono-base-stabilized aluminylene.

A hexane solution of 2 shows a broad absorption band ranging from 500 to $650 \mathrm{~nm}$ in the UV-vis spectrum (Figure S3), which is considerably red-shifted in comparison to those of 1 (346 and 356 $\mathrm{nm}) \cdot{ }^{[8]}$ According to TD-DFT calculations, this absorption is mainly attributed to the lone pair $n \rightarrow \pi / \pi^{*}(H O M O \rightarrow L U M O$, vide infra) transition (Figure S15)
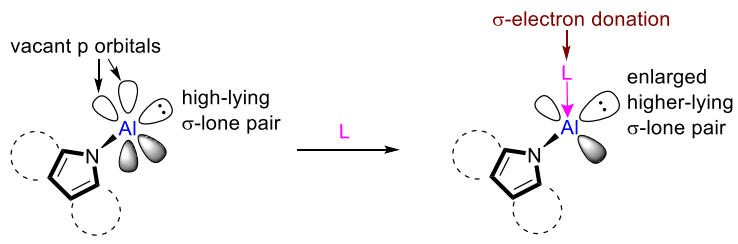

(b)
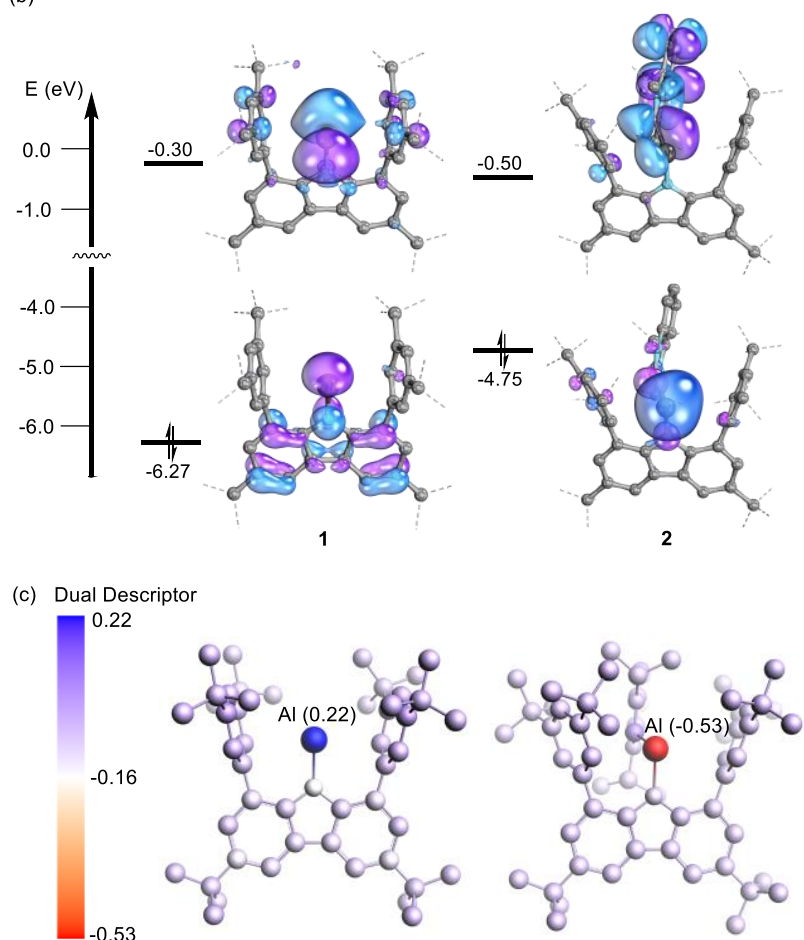

Figure 3. (a) Key changes in frontier orbitals upon ligation of a Lewis base at a free aluminylene. (b) HOMO and LUMO energies of 1 and 2. (c) The condensed values of the dual descriptor that corresponds to the difference between frontier molecular orbitals (FMOs) electron densities

The electronic structure of $\mathbf{2}$ was investigated computationally (Figure 3). We reasoned that the ligation of ${ }^{i} \mathrm{Pr}_{2}$-bimy at Al should lead to a higher-lying HOMO compared to that of 1 due to the $\sigma$ effects while slightly disrupting the energy of the LUMO, which is mainly ruled by the $\pi$-effects (Figure $3 a$ ). Indeed, density functional theory (DFT) calculations at the M06-2X/def2-SVP level of theory reveal that the HOMO of $2(-4.75 \mathrm{eV})$ is predominantly comprised of a $\sigma$-lone pair at $\mathrm{Al}$, while the LUMO $(-0.50 \mathrm{eV})$ displays features of $\pi / \pi^{*}$ orbitals over $\mathrm{Al}$ and the ${ }^{i} \mathrm{Pr}_{2}-$ bimy ligand (Figure 3b). Strikingly, the HOMO-LUMO gap of 2 $(4.25 \mathrm{eV})$ is significantly narrow with respect to that of $1(5.97 \mathrm{eV})$. The natural bond orbital (NBO) explorations of 2 provide Wiberg bond indices (WBIs) of $\mathrm{Al}(1)-\mathrm{C}(1)(0.40)$ and $\mathrm{Al}(1)-\mathrm{N}(1)(0.28)$. Natural population analysis (NPA) demonstrates a less negatively charged $\mathrm{N}(1)$ (-0.88 a.u.) and a less positively charged $\mathrm{Al}(1)(0.68$ a.u.) relative to those in 1 (N: -0.96 a.u.; Al: 0.79 a.u.), ${ }^{[15]}$ implying a slight charge transfer from $\mathrm{N}(1)$ to $\mathrm{Al}(1)$ upon the ${ }^{i} \mathrm{Pr}_{2}$-bimy coordination.

The dual descriptor (DD) calculated from conceptual DFT calculations typically gives an overall description of reactivity behaviors for molecules. ${ }^{[29]}$ Positive or negative values correspond to atomic sites where electrophilicity or nucleophilicity 


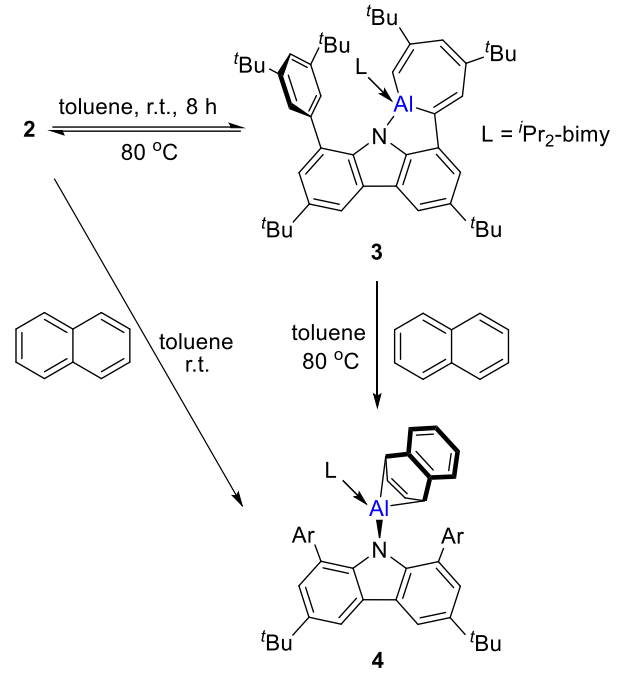

Scheme 1. Synthesis of $\mathbf{3}$ and $\mathbf{4}$. Ar $=3,5$-di-tert-butylphenyl. $\mathrm{L}={ }^{\text {P }} \mathrm{Pr}_{2}$-bimy.

(a)

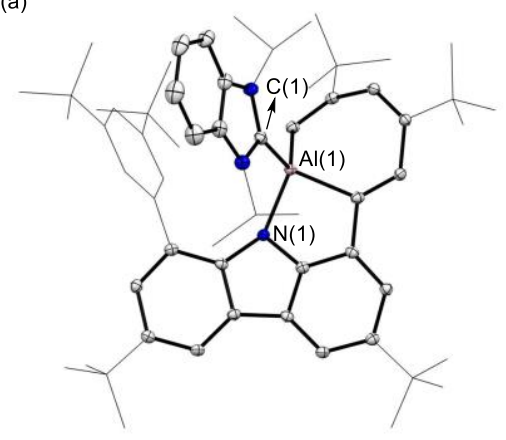

(b)

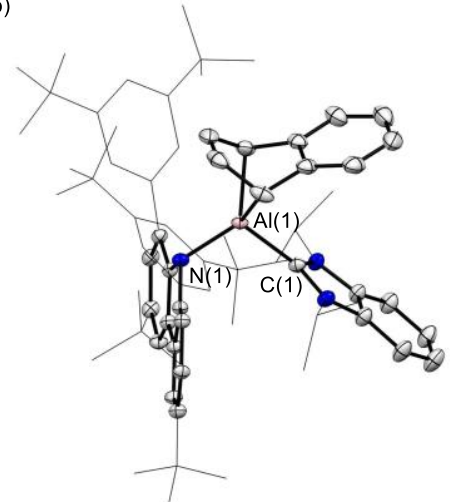

(c)

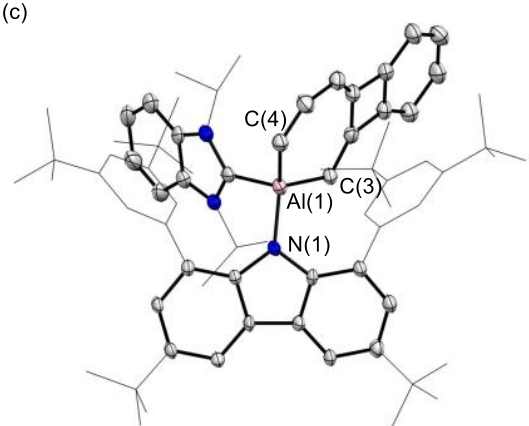

Figure 4. Solid-state structures of 3 (a), 4 (b) and 5 (c). Hydrogen atoms are omitted for clarity. Thermal ellipsoids are set at the $40 \%$ probability level.

is predominant, respectively. Interestingly, we found that albeit the ambiphilic nature of the Al atoms in both 1 and 2 , they reveal completely different dominating chemical behaviors (1: electrophilic; 2 : nucleophilic) as the DD values of $\mathrm{Al}$ in $\mathbf{1}$ and $\mathbf{2}$ are 0.22 and -0.53 , respectively (Figure $3 c$ ). Together, such base coordination strategy is not only capable of modulating the frontier orbitals of aluminylenes, but also reverses the predominant electrophilicity/nucleophilicity at aluminylenes. We thus speculated that 2 should have a higher propensity for small molecule activation compared with $\mathbf{1}$.

Although 2 is stable at ambient temperature in the solid state in the atmosphere of $\mathrm{N}_{2}$ for serveral days, it slowly converted into a new yellow species 3 in solution (i.e. toluene and hexane) within $8 \mathrm{~h}$ (Scheme 1). The ${ }^{1} \mathrm{H}$ NMR spectrum of the isolated product, 3 $\left(\mathrm{C}_{6} \mathrm{D}_{6}\right)$, showed two diagnostic singlets integrating for one proton each in the alkene region (6.55 and $6.53 \mathrm{ppm})$. Single crystals of 3 suitable for an X-ray diffraction study were obtained via slow evaporation of a hexane/ $\mathrm{Et}_{2} \mathrm{O}$ solution at room temperature overnight. To our delight, 3 appeared to contain a newly formed $\mathrm{AlC}_{6}$ seven-membered ring resulting from the insertion of an aluminylene into one of the flanking 3,5-di-tert-butylphenyl groups (Figure $4 \mathrm{a}$ ). The $\mathrm{AlC}_{6}$ ring adopts a boat configuration with the presence of alternating $\mathrm{C}-\mathrm{C}$ and $\mathrm{C}=\mathrm{C}$ bonds and $\mathrm{a}$ tetracoordinate pyramidalized aluminium center. Note that Aldridge, Goicoechea et al. disclosed the benzene ring expansion by a monomeric potassium aluminyl. [30] On the basis of DFT calculations, 2 undergoes a concerted transition state TS1 (free energy of $25.6 \mathrm{kcal} / \mathrm{mol}$ ) to generate $3(-4.5 \mathrm{kcal} / \mathrm{mol}$ ) (Figure S16), which is different from that observed for the benzene ring expansion in which an aromatic $\mathrm{C}-\mathrm{C}$ bond is split in a stepwise fashion. ${ }^{[30]}$ Notably, in line with the experimental observations that 1 is thermally stable at $80^{\circ} \mathrm{C}$ in toluene, ${ }^{[15]} \mathrm{DFT}$ modeling shows that without the ligation of ${ }^{~} \mathrm{Pr}_{2}$-bimy, the similar insertion of $\mathrm{Al}$ in 1 is kinetically unfavorable with an activation barrier of $75.5 \mathrm{kcal} / \mathrm{mol}$ (Figure S17). The formation of $\mathbf{3}$ represents a rare example of main group analogs of the Buchner ring expansion reactions. ${ }^{[30-31]}$

Of particular interest, the transformation of $\mathbf{2}$ and $\mathbf{3}$ was found to be reversible at elevated temperature (Scheme 1). Whereas the combination of 3 and naphthalene in $\mathrm{C}_{6} \mathrm{D}_{6}$ at room temperature showed no reactions, heating this solution at $80^{\circ} \mathrm{C}$ led to a full conversion into a [4+1] cycloaddition product $\mathbf{4}$ (Figure 4b). 4 can also be prepared using 2 and naphthalene at room temperature, reminiscent of recent examples of arene activation by $\mathbf{B} \quad(\mathrm{R}=\mathrm{Me})^{[5 \mathrm{~g},}$ 32] and a dialkylalumanyl anion $\left[\mathrm{CH}_{2}\left(\mathrm{SiMe}_{3}\right)_{2} \mathrm{Cl}_{2} \mathrm{Al}^{-}\right.$.[5f] These results are suggestive of the reversible conversion of 3 to 2 at $80^{\circ} \mathrm{C}$. However, this conversion is very low as we were unable to spectroscopically observe $\mathbf{2}$ in a $\mathrm{C}_{6} \mathrm{D}_{6}$ solution of 3 at $80{ }^{\circ} \mathrm{C}$. Here again, $\mathbf{1}$ is inert towards naphthalene even at $80^{\circ} \mathrm{C}$. Consequently, 3 can behave as a masked reactive aluminylene. Importantly, the regeneration of 2 from 3 undergoes a reductive elimination reaction via $\mathrm{Al}(\mathrm{III}) / \mathrm{Al}(\mathrm{I})$, which is exceedingly rare for Al chemistry ${ }^{[1 d]}$ and may provide hints for further design of novel catalytic cycles based on $\mathrm{Al}(\mathrm{I}) / \mathrm{Al}(\mathrm{III})$.

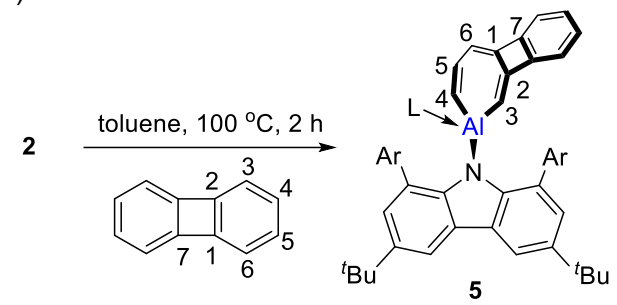

Scheme 2. Synthesis of 5. Ar = 3,5-di-tert-butylphenyl. $L={ }^{i} \mathrm{Pr}_{2}$-bimy

Next, attempts to cleave $\mathrm{C}-\mathrm{C}$ bonds in an intermolecular manner were undertaken (Scheme 2). 4 is thermally robust in toluene at $100{ }^{\circ} \mathrm{C}$. Nonetheless, heating a toluene solution of 2 and biphenylene gave rise to the clean formation of $\mathbf{5}$ in $2 \mathrm{~h}$. To our surprise, X-ray diffraction reveals 5 to be an intermolecular ring expansion product featuring an $\mathrm{AIC}_{6}$ ring analogous to 3 and the weakest central $\mathrm{C}-\mathrm{C} \sigma$-bond ${ }^{[33]}$ remains completely intact (Figure 4c). The oxidative addition of transition metal complexes to biphenylene exclusively splits the weakest $\mathrm{C}-\mathrm{C} \sigma$-bond. ${ }^{[34]}$ Indeed, the scission of the aromatic $\mathrm{C}-\mathrm{C}$ bond of biphenylene has been seldom encountered. ${ }^{[35]}$ Crimmin showed the cooperation of 
two molecules of $\mathbf{B}(\mathrm{R}=\mathrm{Me})$ capable of breaking the $\mathrm{C}(2)-\mathrm{C}(3)$ and $C(4)-C(5)$ bonds of biphenylene, ${ }^{[35]}$ while cleavage of the $\mathrm{C}(1)-\mathrm{C}(2)$ bond by a highly strained dianionic $\mathrm{Al}_{2} \mathrm{O}$ ring species was demonstrated by Kinjo. ${ }^{[36]}$ Notably, the formation of $\mathbf{5}$ is the first example of splitting the $\mathrm{C}(3)-\mathrm{C}(4)$ bond in biphenylene by a single atom center.

DFT mechanistic investigations show the most favorable pathway to $\mathbf{5}$ including four steps (Figure 5). At the outset, the nucleophilic attack of Al towards $\mathrm{C}(1)$ of biphenylene through TS2 $(31.3 \mathrm{kcal} / \mathrm{mol})$ gives a [2+1] cycloaddition product IN1 (-0.8 $\mathrm{kcal} / \mathrm{mol}$ ). Subsequent aluminirane circumambulation furnishes IN3 $(18.4 \mathrm{kcal} / \mathrm{mol})$ via two consecutive $[1,3]$-sigmatropic shifts. Finally, the ring expansion is achieved in TS5 $(25.3 \mathrm{kcal} / \mathrm{mol})$ to form $5(-15.9 \mathrm{kcal} / \mathrm{mol})$. Of note is that IN2 can be isolated and fully characterized when the reaction of 2 and biphenylene was carried out at ambient temperature (Scheme S6). Thermolysis of IN2 cleanly gave $\mathbf{5}$. It is important to note that Crimmin disclosed that the cleavage of the central $C(1)-C(7)$ bond by an ambiphilic Al center is disfavored by both the symmetry and energy of the frontier molecular orbitals of Al. ${ }^{[35]}$

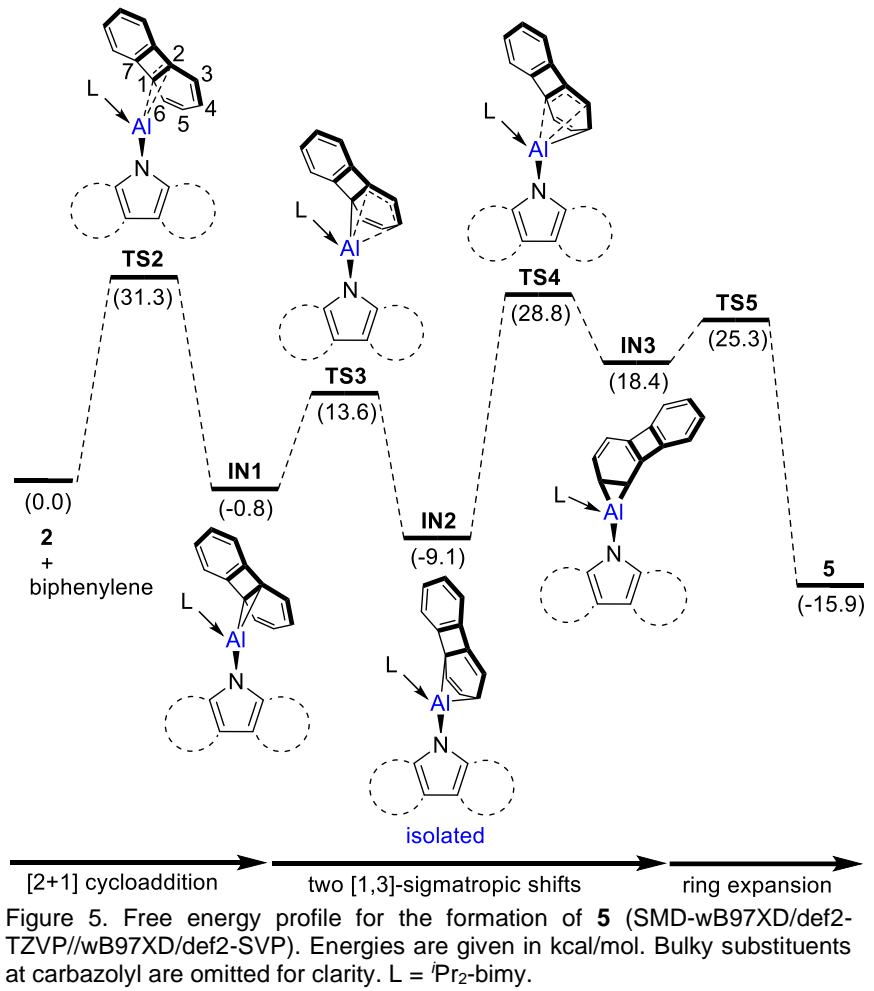

\section{Conclusion}

More than three decades after Bertrand's pioneering work of an isolable singlet carbene, ${ }^{[37]}$ this work demonstrate that its isoelectronic acyclic aluminium analog 2 is synthetically achievable as well. $\mathbf{2}$ is prepared via a simple Lewis base (i.e. ${ }^{2} \mathrm{Pr}_{2-}$ bimy) coordination, which considerably shrinks the HOMO-LUMO gap and thus boosts the redox activity at Al. Unlike the free aluminylene $\mathbf{1}, \mathbf{2}$ exhibits high reactivity for dearomatization of inert arenes via either [4+1] cycloaddition or ring expansion reactions. Given that carbene chemistry has fueled a wide range of fields, we anticipate that with further studies 2 will follow in the footsteps of carbenes and be found in a variety of applications.

\section{Acknowledgements}

We gratefully acknowledge financial support from the National Natural Science Foundation of China (22101114), the Department of Education of Guangdong Province (2021KQNCX079) and SUSTech startup fund (Y01216248). We acknowledge the assistance of SUSTech Core Research Facilities. The theoretical work was supported by the Center for Computational Science and Engineering as well as the CHEM High-Performance Supercomputer Cluster at SUSTech. We thank Drs. Xiaoyong Chang and Yuhui Hua at SUSTech for assistance in X-ray diffraction analyses. Thanks are also given to Dr. David A. Ruiz at BEHR for polishing the article.

\section{Conflict of Interest}

The authors declare no conflict of interest.

Keywords: Aluminylene $\cdot$ Small Molecule Activation $•$ Frontier Orbitals $\cdot$ Arene $\cdot$ Ambiphilicity

(a) P. P. Power, Nature 2010, 463, 171-177; (b) Y. Wang, G. H. Robinson, Inorg. Chem. 2014, 53, 11815-11832; (c) C. Jones, Nat. Rev. Chem. 2017, 1, 0059; (d) T. Chu, G. I. Nikonov, Chem. Rev. 2018, 118, 3608-3680; (e) C. Weetman, S. Inoue, ChemCatChem 2018, 10, 4213-4228; (f) R. L. Melen, Science 2019, 363, 479-484; (g) Y. Su, R. Kinjo, Chem. Soc. Rev. 2019, 48, 3613-3659; (h) M. Batuecas, N. Gorgas, M. R. Crimmin, Chem. Sci. 2021, 12 , 1993-2000.

[2] (a) G. H. Spikes, J. C. Fettinger, P. P. Power, J. Am. Chem Soc. 2005, 127, 12232-12233; (b) Y. Peng, J.-D. Guo, B. D. Ellis, Z. Zhu, J. C. Fettinger, S. Nagase, P. P. Power, J. Am. Chem. Soc. 2009, 131, 16272-16282; (c) Y. Peng, B. D. Ellis, X. Wang, J. C. Fettinger, P. P. Power, Science 2009 325, 1668-1670; (d) R. C. Fischer, P. P. Power, Chem. Rev. 2010, 110, 3877-3923; (e) P. P. Power, Acc. Chem. Res. 2011, 44, 627-637; (f) P. P. Power, Organometallics 2020 , $39,4127-4138$

[3] (a) D. Bourissou, O. Guerret, F. P. Gabbaï, G. Bertrand Chem. Rev. 2000, 100, 39-92; (b) G. D. Frey, V. Lavallo, B. Donnadieu, W. W. Schoeller, G. Bertrand, Science 2007 316, 439-441; (c) Y. Makoto, N. Kyoko, Bull. Chem. Soc. Jpn. 2008, 81, 1377-1392; (d) D. Martin, M. Soleilhavoup G. Bertrand, Chem. Sci. 2011, 2, 389-399; (e) M. Asay, C. Jones, M. Driess, Chem. Rev. 2011, 111, 354-396; (f) M Melaimi, R. Jazzar, M. Soleilhavoup, G. Bertrand, Angew. Chem., Int. Ed. 2017, 56, 10046-10068; (g) M. Soleilhavoup, G. Bertrand, Angew. Chem., Int. Ed. 2017, 56, 1028210292; (h) V. Nesterov, D. Reiter, P. Bag, P. Frisch, R Holzner, A. Porzelt, S. Inoue, Chem. Rev. 2018, 118, 96789842; (i) Y. Liu, J. Li, X. Ma, Z. Yang, H. W. Roesky, Coord. Chem. Rev. 2018, 374, 387-415; (j) M.-A. Légaré, C. Pranckevicius, H. Braunschweig, Chem. Rev. 2019, 119 8231-8261; (k) S. C. Sau, P. K. Hota, S. K. Mandal, M. Soleilhavoup, G. Bertrand, Chem. Soc. Rev. 2020, 49, 1233-1252; (I) C. Shan, S. Yao, M. Driess, Chem. Soc. Rev. 2020, 49, 6733-6754; (m) M. Zhong, S. Sinhababu, H. W. Roesky, Dalton Trans. 2020, 49, 1351-1364; (n) J. Hicks, P. Vasko, J. M. Goicoechea, S. Aldridge, Angew. Chem., Int Ed. 2021, 60, 1702-1713.

[4] (a) G. C. Welch, R. R. S. Juan, J. D. Masuda, D. W. Stephan, Science 2006, 314, 1124-1126; (b) D. W. Stephan, G. Erker, Angew. Chem., Int. Ed. 2015, 54, 6400-6441; (c) D. W Stephan, J. Am. Chem. Soc. 2015, 137, 10018-10032; (d) D. W. Stephan, Science 2016, 354, aaf7229; (e) L. L. Liu, D. W. Stephan, Chem. Soc. Rev. 2019, 48, 3454-3463; (f) A. R. Jupp, D. W. Stephan, Trends Chem. 2019, 1, 35-48.

[5] (a) R. J. Wright, A. D. Phillips, P. P. Power, J. Am. Chem Soc. 2003, 125, 10784-10785; (b) M.-A. Légaré, G. 
Bélanger-Chabot, R. D. Dewhurst, E. Welz, I. Krummenacher, B. Engels, H. Braunschweig, Science 2018, 359, 896-900; (c) M.-A. Légaré, M. Rang, G. BélangerChabot, J. I. Schweizer, I. Krummenacher, R. Bertermann, M. Arrowsmith, M. C. Holthausen, H. Braunschweig, Science 2019, 363, 1329-1332; (d) M.-A. Légaré, G. Bélanger-Chabot, M. Rang, R. D. Dewhurst, I. Krummenacher, R. Bertermann, H. Braunschweig, Nat. Chem. 2020, 12, 1076-1080; (e) B. Rösch, T. X. Gentner, J. Langer, C. Färber, J. Eyselein, L. Zhao, C. Ding, G. Frenking, S. Harder, Science 2021, 371, 1125-1128; (f) K. Sugita, R. Nakano, M. Yamashita, Chem. Eur. J. 2020, 26 2174-2177; (g) S. Brand, H. Elsen, J. Langer, W. A Donaubauer, F. Hampel, S. Harder, Angew. Chem., Int. Ed. 2018, 57, 14169-14173; (h) Y. Su, D. C. Huan Do, Y. Li, R. Kinjo, J. Am. Chem. Soc. 2019, 141, 13729-13733; (i) L. L. Liu, J. Zhou, L. L. Cao, Y. Kim, D. W. Stephan, J. Am. Chem. Soc. 2019, 141, 8083-8087.

[6] C. Dohmeier, C. Robl, M. Tacke, H. Schnöckel, Angew. Chem. Int. Ed. Engl. 1991, 30, 564-565.

[7] A. Hofmann, T. Tröster, T. Kupfer, H. Braunschweig, Chem. Sci. 2019, 10, 3421-3428

[8] C. Cui, H. W. Roesky, H.-G. Schmidt, M. Noltemeyer, H. Hao, F. Cimpoesu, Angew. Chem., Int. Ed. 2000, 39, 42744276.

[9] X. Li, X. Cheng, H. Song, C. Cui, Organometallics 2007, 26 , 1039-1043.

[10] (a) L. L. Liu, J. Zhou, L. L. Cao, D. W. Stephan, J. Am. Chem Soc. 2019, 141, 16971-16982; (b) R. Y. Kong, M. R. Crimmin, J. Am. Chem. Soc. 2020, 142, 11967-11971; (c) A. Dmitrienko, M. Pilkington, J. F. Britten, B. M. Gabidullin A. van der Est, G. I. Nikonov, Angew. Chem., Int. Ed. 2020 59, 16147-16153; (d) M. R. Crimmin, R. Y. Kong, M Batuecas, Chem. Sci. 2021, 10.1039/D1031SC04940B.

[11] G. Tan, T. Szilvási, S. Inoue, B. Blom, M. Driess, J. Am. Chem. Soc. 2014, 136, 9732-9742.

[12] S. K. Mellerup, Y. Cui, F. Fantuzzi, P. Schmid, J. T. Goettel, G. Bélanger-Chabot, M. Arrowsmith, I. Krummenacher, Q. Ye, V. Engel, B. Engels, H. Braunschweig, J. Am. Chem. Soc. 2019, 141, 16954-16960.

[13] J. D. Queen, A. Lehmann, J. C. Fettinger, H. M. Tuononen, P. P. Power, J. Am. Chem. Soc. 2020, 142, 20554-20559.

[14] J. D. Queen, S. Irvankoski, J. C. Fettinger, H. M. Tuononen, P. P. Power, J. Am. Chem. Soc. 2021, 143, 6351-6356.

[15] X. Zhang, L. L. Liu, Angew. Chem., Int. Ed. 2021, 60, 27062-27069

[16] A. Hinz, M. P. Müller, Chem. Commun. 2021, 57, 12532 12535.

[17] (a) J. Hicks, P. Vasko, J. M. Goicoechea, S. Aldridge, Nature 2018, 557, 92-95; (b) M. M. D. Roy, J. Hicks, P. Vasko, A Heilmann, A.-M. Baston, J. M. Goicoechea, S. Aldridge, Angew. Chem., Int. Ed. 2021, 60, 22301-22306; (c) M. M. D. Roy, A. Heilmann, M. A. Ellwanger, S. Aldridge, Angew. Chem., Int. Ed., 10.1002/anie.202112515.

[18] (a) R. J. Schwamm, M. D. Anker, M. Lein, M. P. Coles, Angew. Chem., Int. Ed. 2019, 58, 1489-1493; (b) M. D. Anker, C. L. McMullin, N. A. Rajabi, M. P. Coles, Angew. Chem., Int. Ed. 2020, 59, 12806-12810; (c) M. J. Evans, M. D. Anker, C. L. McMullin, S. E. Neale, M. P. Coles, Angew. Chem., Int. Ed. 2021, 60, 22289-22292.

[19] R. J. Schwamm, M. P. Coles, M. S. Hill, M. F. Mahon, C. L. McMullin, N. A. Rajabi, A. S. S. Wilson, Angew. Chem., Int Ed. 2020, 59, 3928-3932.

[20] (a) K. Koshino, R. Kinjo, J. Am. Chem. Soc. 2020, 142, 9057-9062; (b) K. Koshino, R. Kinjo, Organometallics 2020, $39,4183-4186$.

[21] (a) S. Kurumada, S. Takamori, M. Yamashita, Nat. Chem 2020, 12, 36-39; (b) S. Kurumada, K. Sugita, R. Nakano, M. Yamashita, Angew. Chem., Int. Ed. 2020, 59, 20381-20384.
Soc. 2017, 139, 14384-14387; (b) C. Weetman, P. Bag, T. Szilvási, C. Jandl, S. Inoue, Angew. Chem., Int. Ed. 2019 58, 10961-10965; (c) C. Weetman, A. Porzelt, P. Bag, F. Hanusch, S. Inoue, Chem. Sci. 2020, 11, 4817-4827.

[25] B. Li, S. Kundu, A. C. Stückl, H. Zhu, H. Keil, R. HerbstIrmer, D. Stalke, B. Schwederski, W. Kaim, D. M. Andrada, G. Frenking, H. W. Roesky, Angew. Chem., Int. Ed. 2017, 56, 397-400.

[26] R. L. Falconer, K. M. Byrne, G. S. Nichol, T. Krämer, M. J. Cowley, Angew. Chem., Int. Ed. 2021, 60, 24702-24708.

[27] R. L. Falconer, G. S. Nichol, I. V. Smolyar, S. L. Cockroft, M. J. Cowley, Angew. Chem., Int. Ed. 2021, 60, 2047-2052.

[28] Deposition Numbers 2117022 (2), 2117021 (3), 2117023 (4) 2117025 (5), and 2117024 (IN2) contain the supplementary crystallographic data for this paper. These can be obtained free of charge via www.ccdc.cam.ac.uk/data request/cif.

[29] (a) P. Geerlings, F. De Proft, W. Langenaeker, Chem. Rev. 2003, 103, 1793-1874; (b) C. Morell, A. Grand, A. ToroLabbé, J. Phys. Chem. A 2005, 109, 205-212; (c) P. Geerlings, P. W. Ayers, A. Toro-Labbé, P. K. Chattaraj, F. De Proft, Acc. Chem. Res. 2012, 45, 683-695.

[30] J. Hicks, P. Vasko, J. M. Goicoechea, S. Aldridge, J. Am Chem. Soc. 2019, 141, 11000-11003.

[31] (a) T. A. Perera, E. W. Reinheimer, T. W. Hudnall, J. Am Chem. Soc. 2017, 139, 14807-14814; (b) D. Wendel, A. Porzelt, F. A. D. Herz, D. Sarkar, C. Jandl, S. Inoue, B. Rieger, J. Am. Chem. Soc. 2017, 139, 8134-8137; (c) L. L. Liu, J. Zhou, L. L. Cao, R. Andrews, R. L. Falconer, C. A Russell, D. W. Stephan, J. Am. Chem. Soc. 2018, 140, 147150; (d) L. L. Liu, L. L. Cao, J. Zhou, D. W. Stephan, Angew. Chem., Int. Ed. 2019, 58, 273-277; (e) L. Zhu, J. Zhang, C Cui, Inorg. Chem. 2019, 58, 12007-12010; (f) C. Xu, Z. Ye, L. Xiang, S. Yang, Q. Peng, X. Leng, Y. Chen, Angew. Chem., Int. Ed. 2021, 60, 3189-3195.

[32] C. Bakewell, M. Garçon, R. Y. Kong, L. O'Hare, A. J. P. White, M. R. Crimmin, Inorg. Chem. 2020, 59, 4608-4616.

[33] W. D. Jones, Mechanistic studies of transition metalmediated $\mathrm{C}-\mathrm{C}$ bond activation, Springer Berlin, Heidelberg, Berlin, Heidelberg, 2013

[34] (a) J. J. Eisch, A. M. Piotrowski, K. I. Han, C. Kruger, Y. H Tsay, Organometallics 1985, 4, 224-231; (b) C. Perthuisot, W. D. Jones, J. Am. Chem. Soc. 1994, 116, 3647-3648; (c) C. Perthuisot, B. L. Edelbach, D. L. Zubris, N. Simhai, C. N. Iverson, C. Müller, T. Satoh, W. D. Jones, J. Mol. Catal. A Chem. 2002, 189, 157-168; (d) A. B. Chaplin, R. Tonner, A S. Weller, Organometallics 2010, 29, 2710-2714; (e) H. Takano, T. Ito, K. S. Kanyiva, T. Shibata, Eur. J. Org. Chem 2019, 2019, 2871-2883; (f) D. Frejka, J. Ulč, E. A. B. Kantchev, I. Císařová, M. Kotora, ACS Cat. 2018, 8, 1029010299; (g) H. Takano, T. Ito, K. S. Kanyiva, T. Shibata, Chem. Eur. J. 2018, 24, 15173-15177.

[35] R. Y. Kong, M. R. Crimmin, Angew. Chem., Int. Ed. 2021 60, 2619-2623.

[36] K. Koshino, R. Kinjo, J. Am. Chem. Soc. 2021, 143, 1817218180.

[37] A. Igau, H. Grutzmacher, A. Baceiredo, G. Bertrand, J. Am. Chem. Soc. 1988, 110, 6463-6466. 


\section{Entry for the Table of Contents}

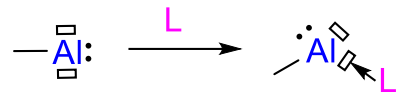

- Small HOMO-LUMO gap

- Activation of inert arenes

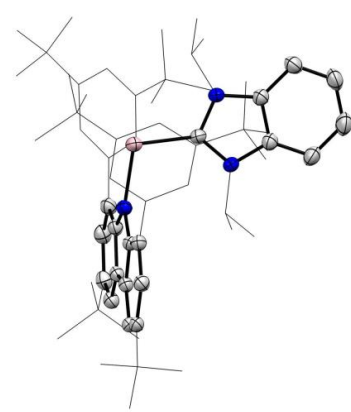

Stabilization or activation? The coordination of an $\mathrm{N}$-heterocyclic carbene at an electron-deficient aluminylene center can remarkably boost the redox property of the aluminylene via modulation of frontier orbitals. This allows for facile dearomatization of inert arenes via either [4+1] cycloadditions or cleavage of aromatic $\mathrm{C}-\mathrm{C}$ bonds.

Institute and/or researcher Twitter usernames: @LLL_lab_SUSTech @SUSTechSZ 